\title{
Uniform Electric Field Distribution in Microwave Heating Applicators by Means of Genetic Algorithms Optimization of Dielectric Multilayer Structures
}

\author{
Elsa Domínguez-Tortajada, Juan Monzó-Cabrera, and Alejandro Díaz-Morcillo, Member, IEEE
}

\begin{abstract}
In this paper, the design of a dielectric multilayer around a clay sample is presented to achieve a uniform electric field distribution over that sample. This structure is located within a multimode microwave-heating oven and is designed by means of genetic algorithms. The permittivity and geometric values for the sample surrounding layers are the selected parameters to be optimized in order to minimize the ratio between the typical deviation and the absolute value of the electric field. The results demonstrate the improvement of the electric field uniformity over the sample using dielectric layers.
\end{abstract}

Index Terms-Dielectric properties, electric field uniformity, genetic algorithms, microwave energy, microwave heating, multimode applicator.

\section{INTRODUCTION}

$\mathbf{T}$ HE ELECTRIC field distribution in a multimode applicator is a combination of all the modes excited in a given frequency range, and usually this distribution is not uniform. If the considered materials have homogeneous properties, the field uniformity is directly related to the temperature distribution in the sample. Therefore, one of the most important and desired characteristics in microwave heating processes is the uniformity of the electric field distribution over the material to be heated because the quality of the process depends on it [1]-[3].

Different methods have been used in order to obtain uniform heating patterns in certain regions. For example, in [4], the sample is placed on a turning tray and a method to simulate the heating process inside domestic microwave ovens is presented.

Mode stirrers are used in [5]-[8] to modify the field distribution inside a multimode cavity. Several studies on these elements prove their good working on multimode applicators, mainly for low-loss materials.

In [9], a procedure to find out the position, structure, and permittivity of certain materials placed inside the applicator is proposed. The parameters of these structures have an effect on the field distribution and they are chosen in order to obtain temperature uniformity over the sample.

A different way of increasing the uniformity is detailed in [10] and [11]. In these studies, the applicator is fed by means of

Manuscript received May 5, 2006; revised July 27, 2006. This work was supported in part by the Fundación Séneca under Project 00700/PPC/04.

The authors are with the Departamento de Tecnologías de la Información y las Comunicaciones, Technical University of Cartagena, Cartagena 30202, Spain (e-mail: elsa.dominguez@upct.es; juan.monzo@upct.es; alejandro.diaz@upct. es).

Digital Object Identifier 10.1109/TMTT.2006.886913 a combination of different sources and mode matching is used to analyze the designs. However, this modal analysis requires canonical structures, i.e., rectangular samples.

Likewise, the use of slotted guides as a feeding system [12] can significantly improve the uniformity [13]-[15], obtaining different field distributions depending on the slots' location.

In [16], the use of two generators and a magic tee adapter for achieving good impedance matching is described. By controlling the signal strength of each source, a better uniformity than using only one magnetron is obtained as well.

The dimensions and geometry of the cavity also have an influence on the field uniformity over the sample. If planar samples must be uniformly heated, a meander applicator can be used [17]. In [18], a single mode modified cylindrical cavity is designed in order to uniformly vulcanize samples of rubber.

In this study, several dielectric layers surrounding the sample are used to obtain electric field uniformity. This differs from the procedure carried out in [19] since, in that study, these dielectric layers were employed in order to optimize load matching. Previous studies [20]-[22] use this configuration as a matching technique as well, and good results were obtained there with efficiencies above $95 \%$. Other studies use dielectric susceptors as a form of active packaging in order to modify temperature profiles when using microwave heating [23].

In [24], Mechenova and Yakovlev emphasize the complexity that implies the optimization of the field pattern and propose optimization methods based on commercial programs that implement the electromagnetic simulation. In this study, a genetic algorithm is presented with the purpose of correctly designing the dielectric and geometric properties of the materials of the structure that will enclose the sample. The application of genetic algorithms to different electromagnetic problems is described in [25]. Several examples, such as [26]-[28], show that it is particularly effective in designing specific electromagnetic systems.

\section{THEORETICAL STUDY}

\section{A. Problem Description}

The procedure followed in this study is similar to the one described in [19]; nevertheless, it is summarized below. The problem to be solved consists of a $24 \times 24 \times 24 \mathrm{~cm}^{3}$ metallic rectangular applicator. The multimode cavity is fed by means of a WR340 waveguide centered at the upper wall of the oven and excited with the $\mathrm{TE}_{10}$ mode around $2.45 \mathrm{GHz}$, which is one of the industrial-scientific-medical (ISM) designated electroheat frequencies [29]. 
The product inside the cavity is clay with relative permittivity $\varepsilon_{r}=24.64-j 5.45$. The clay sample has been chosen to study real industrial dielectric materials that present high values of dielectric constant and loss factor. Although the method can deal with any number of layers, in this study, the sample is surrounded by a maximum of two dielectric layers, whose geometry and permittivities are designed for optimum electric field uniformity.

The genetic algorithm is managed in MATLAB and it uses the CST Microwave Studio commercial software to perform the electromagnetic calculations. CST Microwave Studio applies the finite integration technique and the perfect boundary approximation to solve the considered electromagnetic problems [30]. This full-wave simulator can work with noncanonical structures, although in this study, only rectangular samples are considered.

In this study, the electric field uniformity in the sample must be evaluated and maximized. Therefore, the evaluation function in the genetic algorithm involves the typical deviation of the electric field in the sample surface normalized by the averaged value of the electric field strength in the sample

$$
\bar{\sigma}=\frac{\sqrt{\frac{\sum_{i=1}^{n}\left(\left|E_{i}\right|-\overline{|E|}\right)^{2}}{n}}}{\overline{|E|}}
$$

where $n$ are the points considered in the upper and lower surfaces of the sample. The uniformity control is constrained to the surfaces since a fast electric field drop inwards the sample is assumed due to the consideration of high losses.

Equation (1) must be minimized with the genetic algorithm because the typical deviation considers the electric field variability and, besides, the electric field values on the sample must be maximized. The genetic algorithm is designed to maximize functions and, for this reason, the evaluation function has been computed as

$$
F=\bar{\sigma}_{\max }-\bar{\sigma}
$$

where $\bar{\sigma}_{\max }$ is a positive value higher than the maximum value that the function $\bar{\sigma}$ can achieve and $F$ is used to identify the fitness value. In this case, $\bar{\sigma}_{\max }$ has been set to 2 . This value was assumed high enough since all the simulation values for $\bar{\sigma}$ were always around 1 .

Fig. 1 illustrates the scenario considered in the CST Microwave Studio environment. There, two dielectric layers with variable thickness and permittivity values surround the sample. The waveguide feeding the cavity is also represented. A PTFE $\left(\varepsilon_{r}=2.1-j 0.0003\right)$ tray is included to consider real situations in which transportation or supporting systems are needed.

\section{B. Genetic-Algorithm Implementation}

Genetic algorithms are used to obtain the optimum design in terms of uniformity that, in this particular case, implies obtaining the dielectric and geometric properties of the materials that make up the dielectric structure that encloses the sample. First, it is necessary to define the design parameters, in this case, $\varepsilon_{i}^{\prime}, \varepsilon_{i}^{\prime \prime}$ and $L_{i}$, with $i=1,2$ and their range of variation. A combination of these design parameters constitutes an individual

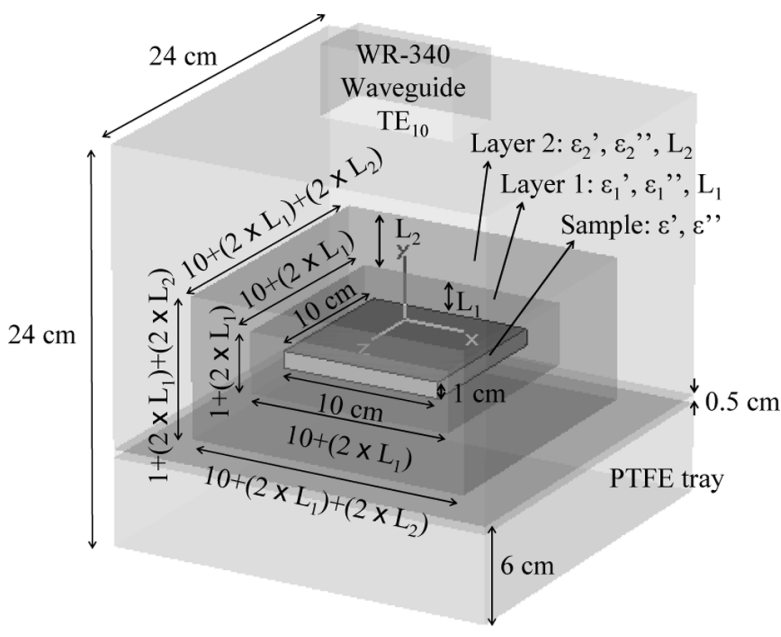

Fig. 1. Layout of sample and multilayer structure inside the applicator.

TABLE I

GENETIC-ALGORITHM PARAMETERS

\begin{tabular}{ll}
\hline \hline QUANTITY & VALUE \\
\hline Design Parameters & $\varepsilon_{1}^{\prime}, \varepsilon_{2}^{\prime}, \varepsilon_{1}^{\prime \prime}, \varepsilon_{2}^{\prime \prime}, L_{1}, L_{2}$ \\
Population & 15 \\
Generations & 15 \\
Selection type & Geometric normalized \\
Crossovers in each generation & 10 \\
Crossover type & Arithmetic crossover \\
Mutations in each generation & 5 \\
Mutation type & Non uniform \\
\hline
\end{tabular}

that is assessed by using the evaluation function that returns as a result the normalized typical deviation (1).

The genetic algorithm is implemented as [19] details. There, the CST full-wave simulator was validated as well.

\section{RESUlTS AND DISCUSSION}

Three different configurations for the dielectric multilayer structure have been considered and optimized by means of the genetic algorithm. In all the evaluated configurations, the input power at the waveguide feeding has been set to $1 \mathrm{~W}$. The simplest structure considered consists of a single dielectric layer $\left(\varepsilon_{1}, L_{1}\right)$ surrounding the sample. More complex structures take into account an additional dielectric layer $\left(\varepsilon_{2}, L_{2}\right)$ and, consequently, the sample is enclosed by two dielectrics. As a particular case of this last configuration, the internal layer has been forced to behave as air in order to simulate a situation in which dielectric contact must be avoided and, as a result, the configuration is sample-air-dielectric. The design parameters, included as input parameters in the optimization process, are the dielectric properties and the thickness of each layer. The variation ranges for the genetic algorithm design parameters have been limited for all scenarios as $\varepsilon^{\prime} \in[1,10], \varepsilon^{\prime \prime} \in[0.01,0.05]$, and $L \in[1,3.5] \mathrm{cm}$. Table I shows the genetic-algorithm configuration that has been established after a study of the problem behavior.

Firstly, the evaluation of the system without dielectric layers has been considered to obtain the electric field distribution in 


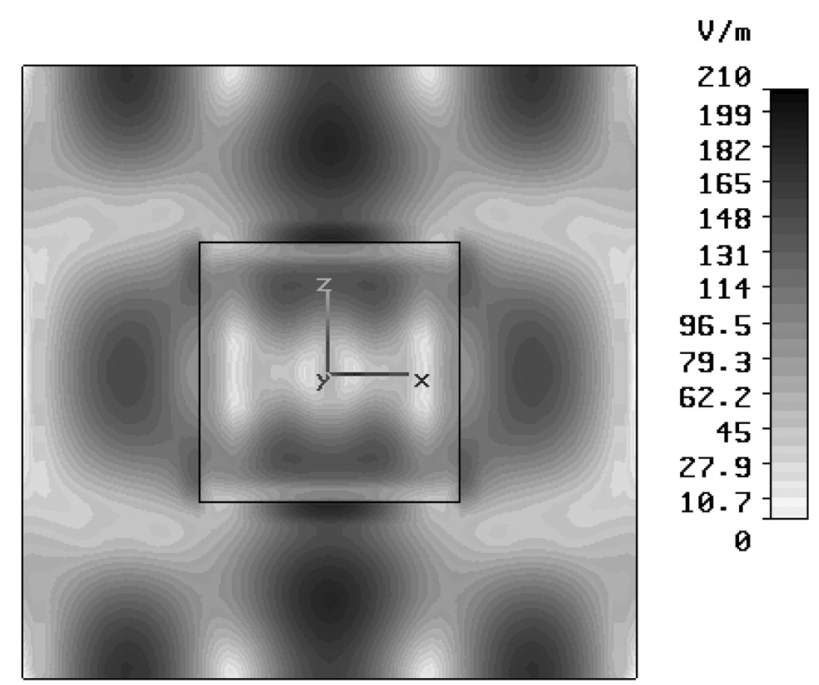

Fig. 2. Electric field over the clay sample and inside the applicator for the configuration without dielectric layers.

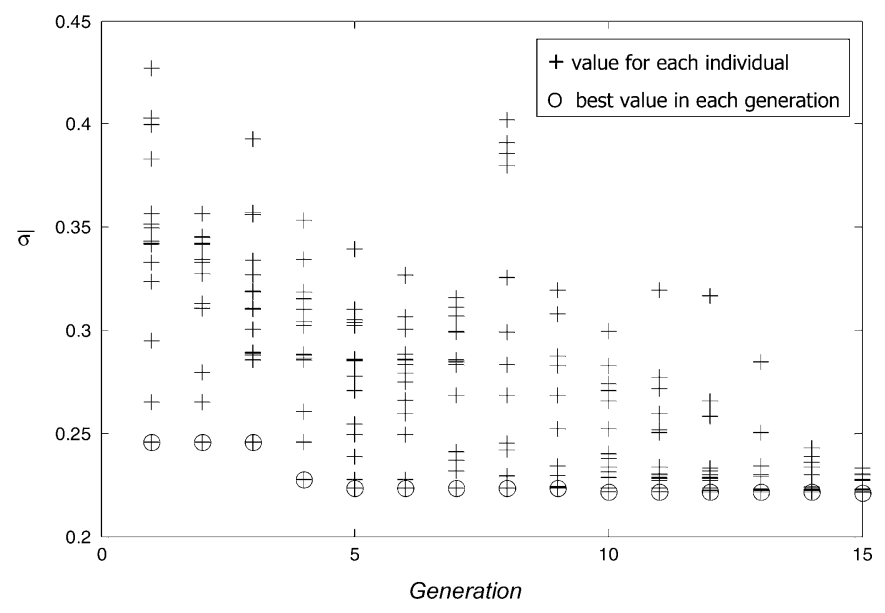

Fig. 3. Genetic-algorithm evolution in the one-layer design.

the sample. This study is useful to verify the improvement in uniformity achieved with the optimized layers.

Fig. 2 shows the computed electric field pattern over the sample. From this result, one can conclude that the electric field is mainly concentrated on two hot spots by the sides of the sample, which leads to an uneven electric field pattern. In this case, the average of the electric field in the sample is $105.7 \mathrm{~V} / \mathrm{m}$ and the normalized typical deviation is 0.771 .

For the one-layer configuration, Fig. 3 shows the genetic-algorithm evolution and the convergence of all the individuals of the population to fitness values close to the best one. In order to better appreciate the minimization process, we depict the $\bar{\sigma}$ trend instead of $F$, which is maximized by the genetic algorithm and depends on a not optimized constant such as $\bar{\sigma}_{\max }$. The optimized parameters are, in this case, $\varepsilon_{1}^{\prime}=6.469, \varepsilon_{1}^{\prime \prime}=0.0284$, and $L_{1}=2.625 \mathrm{~cm}$. With these features, the multimode structure yields a normalized typical deviation equal to 0.221 and the electric field mean is $228.9 \mathrm{~V} / \mathrm{m}$.

Thus, the electric field value has been increased from 105.7 to $228.9 \mathrm{~V} / \mathrm{m}$ and the typical deviation has decreased from 81.5 to $50.6 \mathrm{~V} / \mathrm{m}$. Consequently, that structure really achieves better

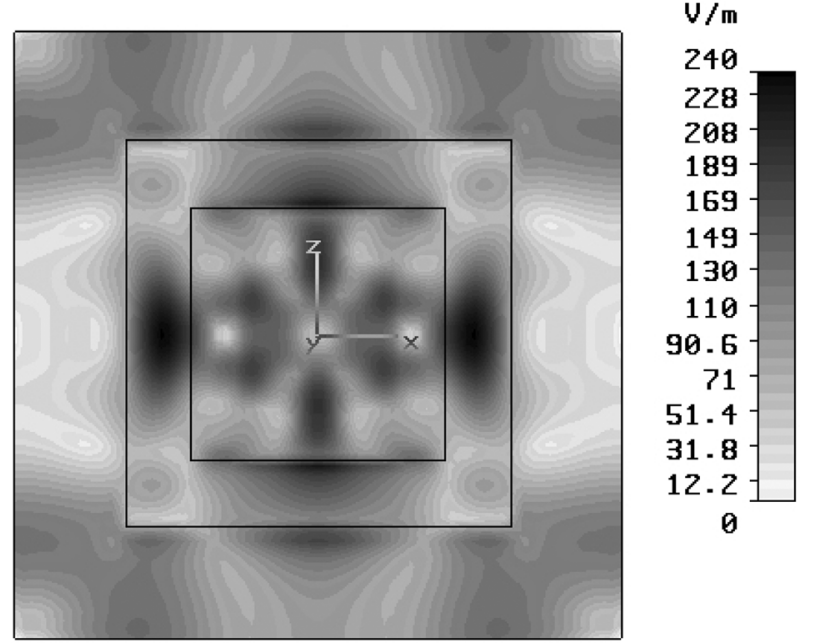

Fig. 4. Electric field over the clay sample and inside the applicator for the onelayer configuration.

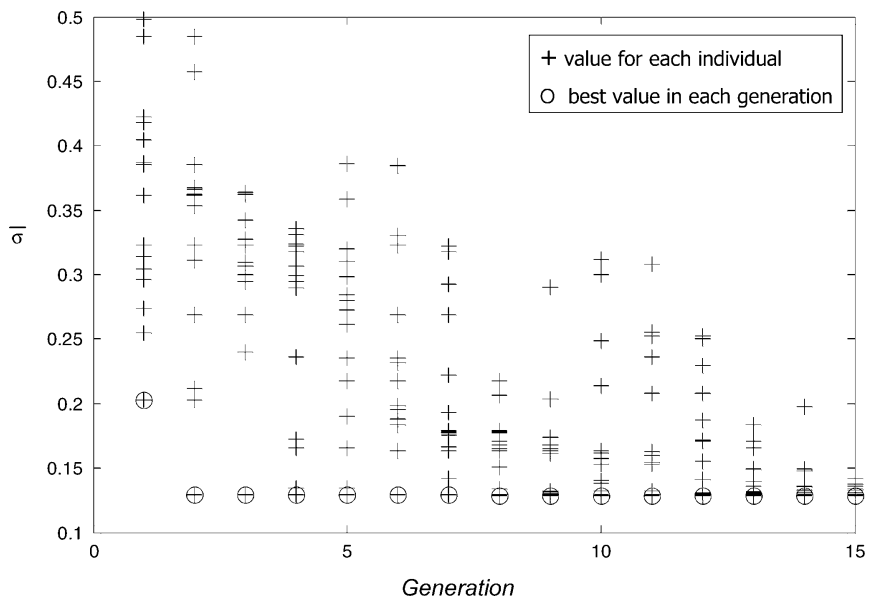

Fig. 5. Genetic-algorithm evolution in the two-layer design.

uniformity and a higher electric field average than the structure without layers. Fig. 4 depicts the electric field inside the applicator.

If the power efficiency is defined as the ratio between the absorbed power by the sample and the incident power into the cavity, a deeper analysis on this aspect can be done. In fact, the power efficiency for the configuration without layers is $31.8 \%$. By adding the optimized dielectric layer. the power efficiency increases up to $62.85 \%$ and, consequently, it represents an enhancement in the absorbed energy by the sample.

Next, the electric field uniformity is analyzed for the design with two dielectric layers. The best value for the normalized typical deviation achieved is 0.1284 and the average of the electric field in the sample is $168.2 \mathrm{~V} / \mathrm{m}$ with $\varepsilon_{1}^{\prime}=5.325, \varepsilon_{1}^{\prime \prime}=$ $0.0369, L_{1}=2.3034 \mathrm{~cm}, \varepsilon_{2}^{\prime}=3.567, \varepsilon_{2}^{\prime \prime}=0.031$, and $L_{2}=$ $3.042 \mathrm{~cm}$. Fig. 5 depicts the evolution of the genetic algorithm. There, it can be observed that a good optimization has been achieved in the second generation; nevertheless, there are no more improvements in the following generations.

The electric field in the sample in this two-layer structure is smaller than in the single-layer design, but it is more uniform. 


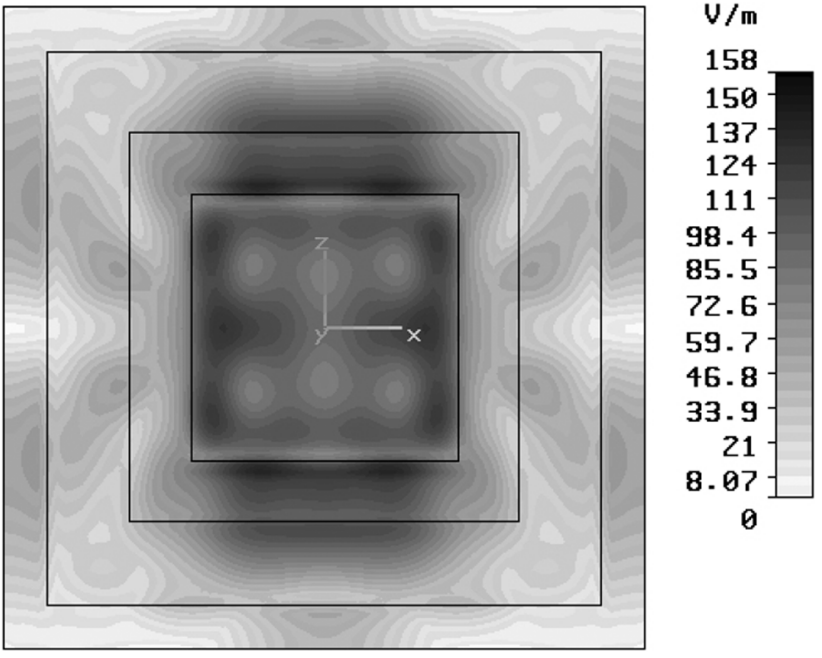

Fig. 6. Electric field over the sample and inside the applicator for the two-layer configuration.

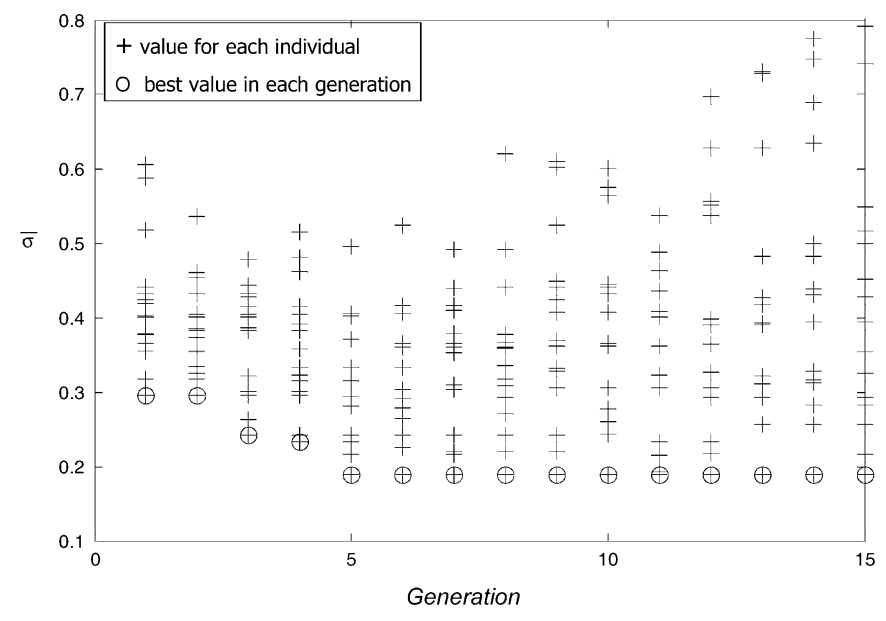

Fig. 7. Genetic-algorithm evolution in the two-layer design considering air the internal one.

Fig. 6 shows the electric field for the upper surface plane. A high-quality uniform field over the sample can be observed.

In this case, the power efficiency reaches $37.15 \%$, which is better than in the case of using no external dielectric. On the other side, the layers also absorb energy; the internal mold absorbs $7.6 \%$ and the external one absorbs $32.4 \%$. This points out that a compromise solution between uniformity and efficiency would be the best design strategy.

The last design analyzed here consists of two layers, considering air material for the internal one, as previously explained. For this configuration, the genetic-algorithm evolution is depicted in Fig. 7, where the best value for the normalized typical deviation is 0.1887 and the average of the electric field in the sample is $154.5 \mathrm{~V} / \mathrm{m}$. A progressive optimization for the best individual can be observed along the first five generations.

The best design in this case consists of the following values for the design parameters: $L_{1}=2.732 \mathrm{~cm}, \varepsilon_{2}^{\prime}=2.657, \varepsilon_{2}^{\prime \prime}=$ 0.04407 , and $L_{2}=2.919 \mathrm{~cm}$. This design shows better electric field uniformity when compared to the design without layers,

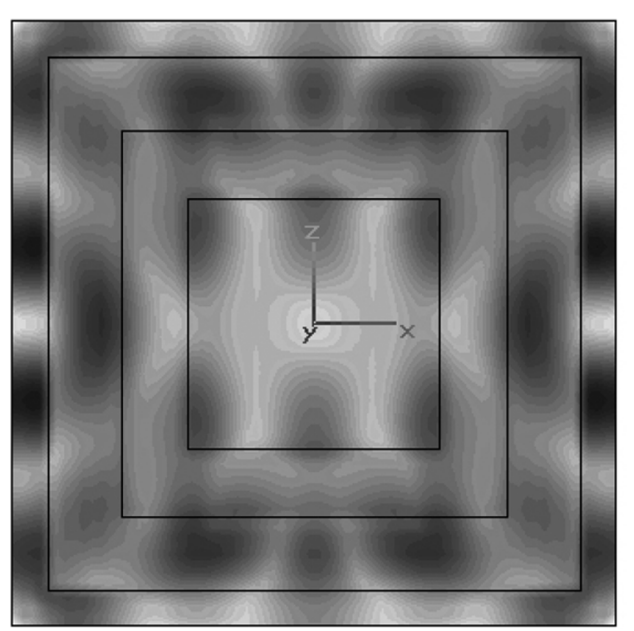

Fig. 8. Electric field over the sample and inside the applicator for the air + dielectric configuration.

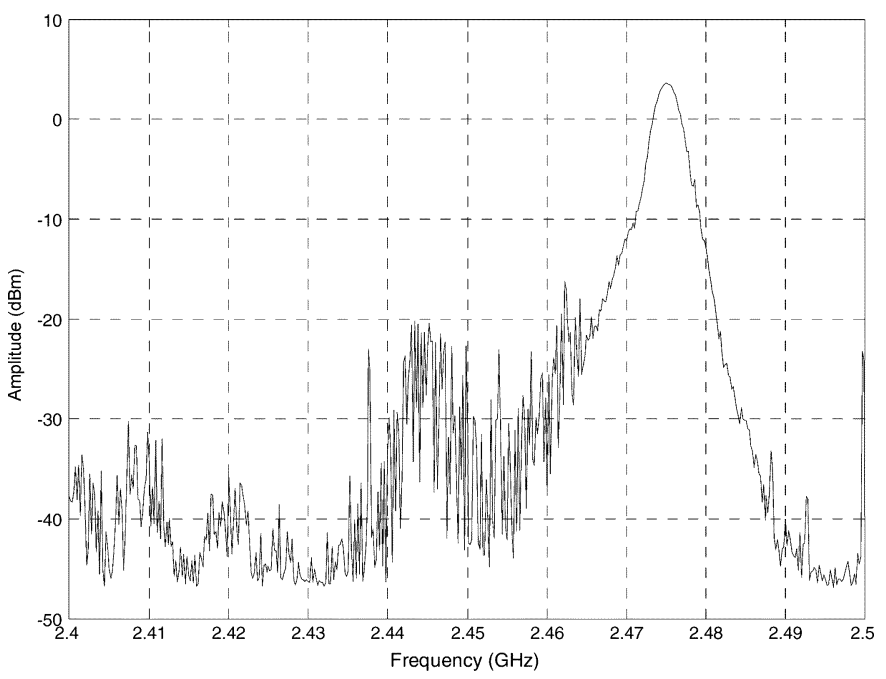

Fig. 9. Spectrum of the magnetron employed in the experience.

but the optimum two-layer design is better regarding the uniformity and the electric field strength in the sample.

Fig. 8 illustrates the electric field distribution in the upper surface of the sample.

From these results, one can conclude that there is a good optimization evolution, but the normalized typical deviation for this configuration is worse. This is consistent with the reduction in the degrees of freedom in the design.

\section{EXPERIMENTAL VALIDATION}

In order to validate the simulation procedure and to check the changes in the electric field pattern using dielectric layers, the following tests have been performed. A $32 \times 32 \times 32 \mathrm{~cm}^{3}$ cavity has been fed by means of a magnetron with the spectrum illustrated in Fig. 9. The spectrum has been measured by means of the Rhode ZVRE spectrum analyzer. It can be observed from this measurement that the magnetron oscillates at $2.475 \mathrm{GHz}$ instead of the assumed $2.45 \mathrm{GHz}$ for these types of devices. Therefore, all simulations in this section were carried out at the former frequency. 


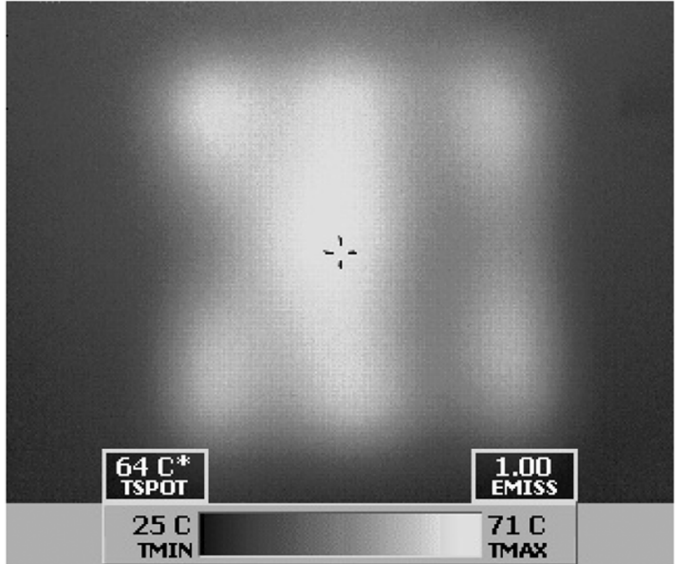

(a)

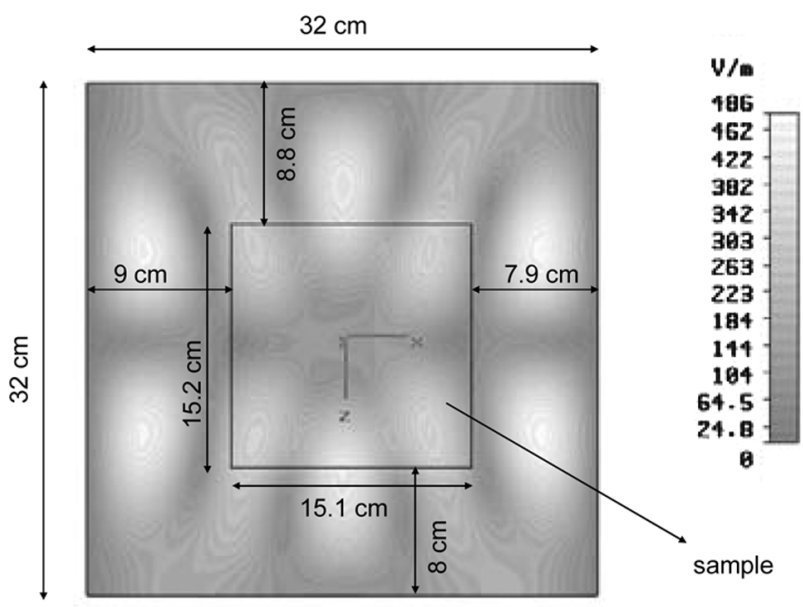

(b)

Fig. 10. (a) Thermography of the wood sample. (b) Computer simulation with the same configuration.

The cavity was loaded with a $15.1 \times 15.2 \times 1.7 \mathrm{~cm}^{3}$ piece of wood with $\varepsilon_{r}=2.0086-j 0.185$. This sample was located inside the cavity leaving 8.8 and $9 \mathrm{~cm}$ from the walls of the applicator and it was irradiated during $46 \mathrm{~s}$ at a $600-\mathrm{W}$ power level. The thermographic camera CYCLOPS PPM+ was used in order to obtain the temperature patterns across the sample. The CST Microwave Studio simulator was used in order to compare those temperature profiles with the electric field distribution.

Fig. 10(a) shows the temperature distribution at the wood sample, while Fig. 10(b) depicts the electric field distribution at $2.475 \mathrm{GHz}$. Similar patterns can be observed in both images. However, the differences between both figures might be due to thermal migration during and after microwave irradiation since the thermography was taken $90 \mathrm{~s}$ after the generator stopped due to the time employed in opening the cavity.

After a cooling period, the sample was covered with a $15.1 \times 15.2 \times 1.1 \mathrm{~cm}^{3}$ PTFE layer with $\varepsilon_{r}=2.1-j 0.0003$. It was irradiated during $62 \mathrm{~s}$ at a $600-\mathrm{W}$ power level. By using the thermographic camera, the temperature pattern shown in Fig. 11(a) was obtained. Fig. 11(b) illustrates the electric field distribution computed by the electromagnetic simulator. Once again, the distribution of the main lobes is very similar in both images. The thermography was taken $60 \mathrm{~s}$ after the generator stopped.

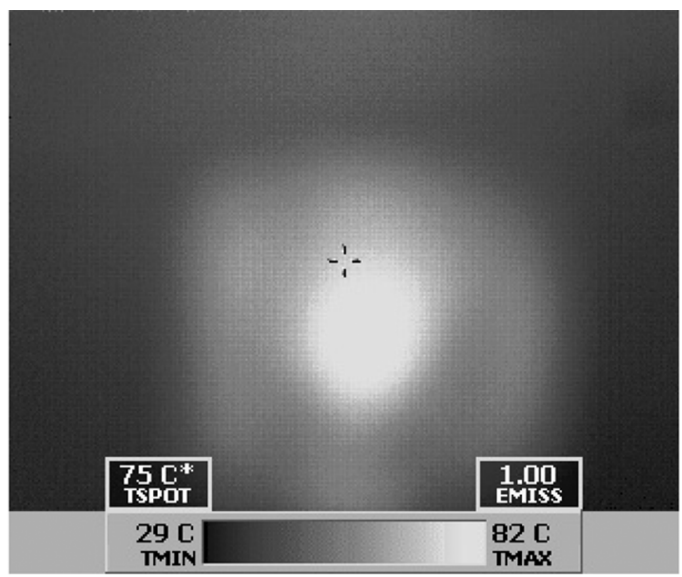

(a)

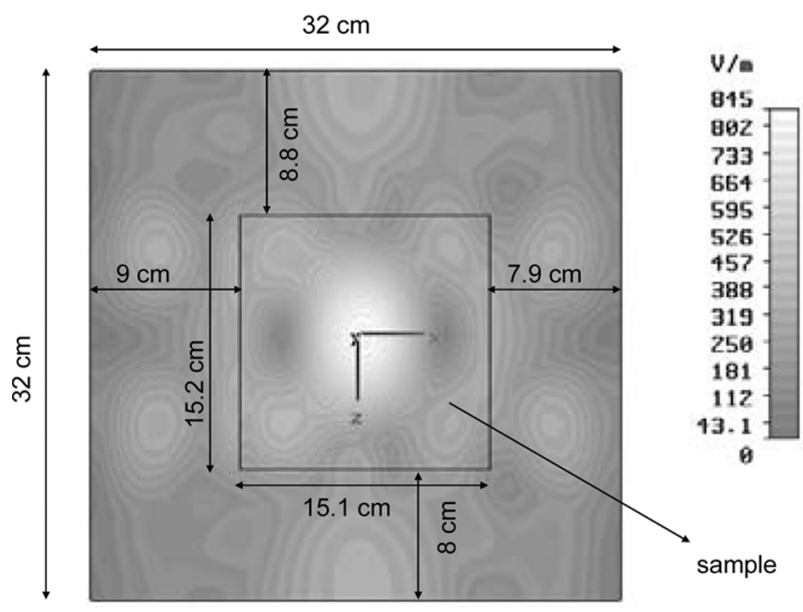

(b)

Fig. 11. (a) Thermography of the wood sample using the PTFE layer. (b) Computer simulation with the same configuration.

By comparing experimental data in Figs. 10 and 11, one can observe that the insertion of a dielectric mould highly changes the spatial distribution of the electric field and, accordingly, the temperature patterns.

It must be remarked that the proposed procedure for obtaining uniform electric field distributions is, at the moment, difficult to implement since it requires very precise material permittivity values. However, the experimental validation shows that this approach is accurate enough to correctly predict the temperature patterns and the changes that the dielectric layers may produce on them.

\section{CONCLUSION}

The use of dielectric layers surrounding a high-loss dielectric product to achieve electric field uniformity for multimode microwave-heating ovens has been presented. A genetic algorithm optimization procedure has been used in order to obtain the optimum values of the dielectric molds around the sample, namely, permittivity and thickness.

The results for three configurations show that the electric field uniformity is better using dielectric layers. The best performance was reached by the two-layer structure. However, a relationship among the typical deviation, the mean electric field 
intensity in the sample, and the power efficiency of the process is perceived and, depending on the microwave heating application, a compromise among these three parameters must be established.

When comparing this technique with mode-stirring results obtained in [7] and [8], one can conclude that this technique is capable of avoiding edge overheating and, thus, it is a better alternative for producing a more uniform electric field distribution when high-loss materials must be heated.

The uniformity results obtained here, together with those obtained in [19] for matching purposes, show that this technique is actually a potential method to solve ordinary problems in microwave heating.

Finally, it must be remarked that despite the fact that the technique described in this paper shows good promise, the practical implementation requires very precise material manufacturing to obtain the designed permittivity values. Future research is envisaged in order to design this kind of multilayer structures with commercial materials.

\section{REFERENCES}

[1] A. C. Metaxas and R. J. Meredith, Industrial Microwave Heating. London, U.K.: Peregrinus, 1986.

[2] T. V. Chow-Ting-Chan and H. C. Reader, Understanding Microwave Heating Cavities. London, U.K.: Artech House, 2000.

[3] G. Roussy and J. A. Pearce, Foundations and Industrial Applications of Microwave and Radiofrequency Fields, Physical and Chemical Processes. New York: Wiley, 1996.

[4] P. Kopyt and M. Celuch-Marcysiak, "FDTD modelling and experimental verification of electromagnetic power dissipated in domestic microwave ovens," J. Telecommun. Inf. Technol., no. 1, pp. 59-65, 2003.

[5] J. Monzó-Cabrera, "Estudio del secado asistido por microondas en los materiales laminares," Ph.D. dissertation, Dept. Telecommun. Eng., Polytech. Univ. Valencia, Valencia, Spain, 2002.

[6] J. Monzó-Cabrera, J. M. Catalá-Civera, P. Plaza-González, and D. Sánchez-Hernández, "A model for microwave-assisted drying of leather: Development and validation," J. Microw. Power Electromagn. Energy, vol. 39, no. 1, pp. 53-64, 2004.

[7] P. Plaza-Gonzalez, J. Monzó-Cabrera, J. M. Catalá-Civera, and D. Sánchez-Hernández, "Effect of mode-stirrer configurations on dielectric heating performance in multimode microwave applicators," IEEE Trans. Microw. Theory Tech., vol. 53, no. 5, pp. 1699-1706, May 2005.

[8] _ - "New approach for the prediction of the electric field distribution in multimode microwave-heating applicators with mode stirrers," IEEE Trans. Magn., vol. 40, no. 3, pp. 1672-1678, May 2004.

[9] K. A. Lurie and V. V. Yakovlev, "Method of control and optimization of microwave heating in waveguide systems," IEEE Trans. Magn., vol. 35, no. 3, pp. 1777-1780, May 1999.

[10] J. Pitarch, A. J. Canós, F. L. Peñaranda-Foix, J. M. Catalá-Civera, and J. V. Balbastre, "Synthesis of uniform electric field distributions in microwave multimode applicators by multifeed techniques," in 9th Int. Microw. High-Freq. Heating Conf., Loughborough, U.K., Sep. 1-5, 2003, pp. 221-224.

[11] J. M. Catalá-Civera, J. Pitarch, M. Contelles-Cervera, F. PeñarandaFoix, and J. V. Balbastre, "On the possibilities of multifeeding techniques to improve the electric field uniformity in multimode microwave applicators," in 10th Int. Microw. High-Freq. Heating Conf., Modena, Italy, Sep. 12-15, 2005, pp. 360-363.

[12] S. Keller, G. Roussy, B. Maestrali, and J. M. Thiebaut, "Experimental and theoretical study of waveguide slot radiators," in 6th Int. Microw. High-Freq. Heating Conf., Fermo, Italy, Sep. 8-12, 1997, pp. 321-325.

[13] J. A. Cebrián-Gascón, E. de los Reyes, and D. Sánchez-Hernández, "Use of commercial electromagnetic simulators for uniformity enhancement of slotted waveguide-fed microwave heating applicators," in 7th Int. Microw. High-Freq. Heating Conf., Valencia, Spain, Sep. $13-17,1999$, pp. $225-228$.
[14] V. V. Stepanov, "The multielement excitation for improvement of uniformity microwave energy distribution for partly filled rectangular microwave chamber," in 7th Int. Microw. High-Freq. Heating Conf., Valencia, Spain, Sep. 13-17, 1997, pp. 173-176.

[15] S. Stanculovic, L. Feher, and M. Thumm, "Optimization of slotted waveguides for $2.45 \mathrm{GHz}$ applicators," in 9th Int. Microw. High-Freq. Heating Conf., Loughborough, U.K., Sep. 1-5, 2003, pp. 313-316.

[16] G. Roussy and N. Kongmark, "Improving electric field distribution in a microwave heating device," J. Microw. Power Electromagn. Energy, vol. 35 , no. 4, pp. 253-257, 2000.

[17] S. Frandos, "Numerical modeling of heating thin dielectric sheets with a microwave applicator of meanders type," in 7th Int. Microw. HighFreq. Heating Conf., Valencia, Spain, Sep. 13-17, 1999, pp. 187-190.

[18] J. M. Catalá Civera, S. Giner Maravilla, D. Sánchez Hernández, and E. de los Reyes, "Pressure-aided microwave rubber vulcanization in a ridged three-zone cylindrical cavity," J. Microw. Power Electromagn. Energy, vol. 35, no. 2, pp. 92-104, 2000.

[19] E. Domínguez-Tortajada, J. Monzó-Cabrera, and A. Díaz-Morcillo, "Load matching in microwave-heating applicators by means of genetic algorithms optimization of dielectric multilayer structures," Microw. Opt. Technol. Lett., vol. 47, no. 5, pp. 426-430, Dec. 2005.

[20] J. Monzó-Cabrera, A. Díaz-Morcillo, J. L. Pedreño-Molina, and D. Sánchez-Hernández, "A new method for load matching in multimodemicrowave heating applicators based on the use of dielectric-layer superposition," Microw. Opt. Technol. Lett., vol. 40, no. 4, pp. 318-322, Feb. 2004.

[21] J. Monzó-Cabrera, J. Escalante, A. Díaz-Morcillo, A. MartínezGonzález, and D. Sánchez-Hernández, "Load matching in multimode microwave-heating applicators based on the use of dielectric layer moulding with commercial materials," Microw. Opt. Technol. Lett., vol. 41, no. 5, pp. 414-417, Feb. 2004.

[22] J. Monzó-Cabrera, E. Domínguez-Tortajada, A. Díaz-Morcillo, J. M. Catalá-Civera, and D. Sánchez-Hernández, "On the possibilities of load matching in microwave applicators using dielectric layer superposition around the sample," in 9th Int. Microw. High-Freq. Heating Conf., Loughborough, U.K., Sep. 1-5, 2003, pp. 309-312.

[23] M. Sato, "Recent development of microwave kilns for industries in Japan," in Proc. 3rd Microw. Radio Freq. Applicat. World Congr., Sydney, Australia, Sep. 2002, pp. 281-289.

[24] V. A. Mechenova and V. V. Yakovlev, "Efficiency optimization for systems and components in microwave power engineering," J. Microw. Power Electromagn. Energy, vol. 39, no. 1, pp. 15-28, 2004.

[25] Y. Rahmat-Samii and E. Michielssen, Electromagnetic Optimization by Genetic Algorithms, ser. Microw. Opt. Eng.. New York: Wiley, 1999.

[26] S. Chakravarty and R. Mittra, "Design of microwave filters using a binary-coded genetic algorithm," Microw. Opt. Technol. Lett., vol. 26, no. 3, pp. 162-166, Aug., 200.

[27] D. Suckley, "Genetic algorithm in the design of FIR filters," Proc. Inst. Elect. Eng.-G: Circuits, Devices, Syst., vol. 138, no. 2, pp. 234-238, Apr. 1991.

[28] S. P. Panthong and S. Jantarang, "3G mobile wireless routing optimization by genetic algorithm," in IEEE Can. Elect. Comput. Eng. Conf., Bangkok, Thailand, May 4-7, 2003, vol. 3, pp. 1597-1600.

[29] A. C. Metaxas, Foundations of Electroheat: A Unified Approach. New York: Wiley, 1996.

[30] "CST Microwave Studio Manual, HF Design and Analysis," ver. 5th, CST, Darmstadt, Germany, 2004.

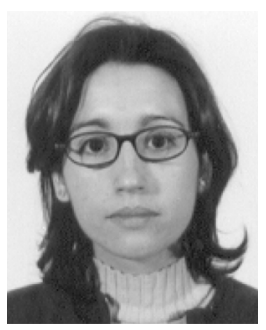

Elsa Domínguez-Tortajada was born in Valencia, Spain, in June 1976. She received the Dipl. Ing. degree in telecommunications engineering from the Universidad Politécnica de Valencia, Valencia, Spain, in 2001, and the Ph.D. degree from the Universidad Politécnica de Cartagena, Cartagena, Spain, in 2005 .

In 2002, she joined the Departamento de Tecnologías de la Información y las Comunicaciones, Universidad Politécnica de Cartagena, where she is currently an Associate Lecturer. She currently combines her teaching and researching activities in different areas, which cover microwave-assisted heating processes, microwave applicators design and optimization, and numerical techniques in electromagnetics. 


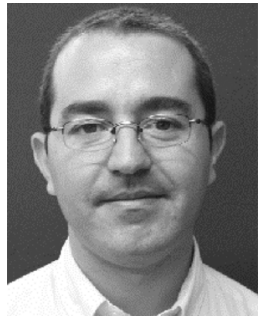

Juan Monzó-Cabrera was born in Elda (Alicante), Spain, in January 1973. He received the Dipl. Ing. and Ph.D. degrees in telecommunications engineering from the Universidad Politécnica de Valencia, Valencia, Spain, in 1998 and 2002, respectively.

From 1999 to 2000, he was a Research Assistant with the Microwave Heating Group (GCM). In 2000, he joined the Departamento de Teoría de la Señal y Radiocomunicaciones, Universidad Politécnica de Cartagena, Cartagena, Spain, as an Associate Lecturer. He is currently an Associate Lecturer with the Departamento de Tecnologías de la Información y Comunicaciones, Universidad Politécnica de Cartagena. He has coauthored over 40 papers in referred journals and conference proceedings. He holds several patents regarding microwave heating industrial processes. He is a Reviewer for several international journals. His current research areas cover microwave-assisted heating and drying processes, microwave applicator design and optimization, and numerical techniques in electromagnetics.

Dr. Monzó-Cabrera is a member of the Association of Microwave Power in Europe for Research and Education (AMPERE), a European-based organization devoted to the promotion of RF and microwave energy.

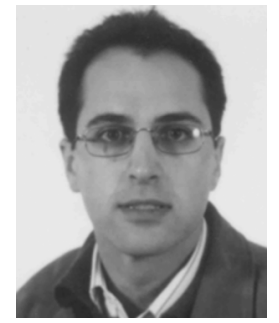

Alejandro Díaz-Morcillo (S'95-M'02) was born in Albacete, Spain, in 1971. He received the Ingeniero (Ms. Eng.) and Doctor Ingeniero (Ph.D.) degrees in telecommunication engineering from the Polytechnic University of Valencia (UPV), Valencia, Spain, in 1995 and 2000, respectively.

From 1996 to 1999, he was a Research Assistant with the Department of Communications, UPV. In 1999, he joined the Departamento de Tecnologías de la Información y las Comunicaciones, Universidad Politécnica de Cartagena (UPCT), Cartagena, Spain, as Teaching Assistant, where, since 2001, he has been an Associate Professor. He leads the Electromagnetics and Matter Research Group, UPCT. His main research interests are numerical methods in electromagnetics, electromagnetic compatibility (EMC), and industrial microwave heating systems. 